Paraty, totaling 1024 skills The cases are grouped according to occupational group, diagnoses, productive sector and age group and comparing the incidence and severity between the groups. Only cases of temporary incapacity limited to the maximum period of 2 years were studied.

Results The less educated workers, the primary and the male sector showed an extended period of disability. The main diagnosis of disability was according to ICD-10: lesions (group XIX), diseases of the musculoskeletal system (GROUP XIII), blood disease (GROUP II), circulatory group disease (GROUP IX), diseases of the digestive tract).

Discussion The results demonstrate an effect of productive restructuring in our country with the prevalence of diseases classic professionals with decreased prevalence of chronic degenerative diseases and work - related. Most of the lesions are connected to the means of transport (only 2 out of 258 were typical work accidents). These results require a need for articulation of preventive policies in addition to the Occupational Medicine service and training of occupational health professionals for the recognition and prevention of a new epidemiological picture of Brazilian workers.

\section{OCCUPATIONAL DISEASE AND MORBIDITY MODELLING}

${ }^{1} Y$ Samant, ${ }^{2} \mathrm{HM}$ Gravseth, ${ }^{3} \mathrm{O}$ Aas, ${ }^{1} \mathrm{R}$ Ekle, ${ }^{1} \mathrm{~T}$ Stromholm*, ${ }^{4} \mathrm{~V}$ Gigonzac*, ${ }^{4} \mathrm{I}$ KhireddineMedouni, ${ }^{4} E$ Breuillard, ${ }^{4} \mathrm{C}$ Bossard, ${ }^{4}$ Guseva Canu, ${ }^{4} \mathrm{G}$ Santin, ${ }^{4} \mathrm{~L}$ Chérié-Challine, ${ }^{5} \mathrm{~T}$ Bonney* ${ }^{*}{ }^{5} \mathrm{E}$ Kyeremateng-Amoah, ${ }^{5} \mathrm{~L}$ Forst, ${ }^{5} \mathrm{~L}$ Friedman, ${ }^{6,7} \mathrm{AC}$ Pesatori, ${ }^{6} \mathrm{~L}$ Angelici, ${ }^{6} \mathrm{C}$ Favero, ${ }^{6} \mathrm{~L}$ Dioni, ${ }^{7} \mathrm{C}$ Mensi, ${ }^{8} \mathrm{C}$ Bareggi, ${ }^{9} \mathrm{~A}$ Palleschi, ${ }^{6} \mathrm{~L}$ Cantone, ${ }^{7} \mathrm{D}$ Consonni, ${ }^{7} \mathrm{~L}$ Bordini, ${ }^{2} \mathrm{~A}$ Todaro, ${ }^{6,7} \mathrm{~V}$ Bollati. 'Norwegian Labour Inspection Authority, Norway; ${ }^{2}$ National Institute of Occupational Health, Norway; ${ }^{3}$ St. Olav's Hospital, Division of occupational medicine, Norway; ${ }^{4}$ Santé Publique France, French Public Health Agency, Direction of Occupational Health, Saint-Maurice, France; ${ }^{5}$ University of Illinois at Chicago, School of Public Health, Environmental and Occupational Health Sciences, Chicago, USA; ${ }^{6}$ EPIGET Lab - Dept. Clinical Sciences and Community Health, Università degli Studi di Milano, Milan, Italy; 'Fondazione IRCCS Ca' Granda Ospedale Maggiore Policlinico, Occupational Medicine Unit, Milan, Italy; ${ }^{8}$ Fondazione IRCCS Ca' Granda Ospedale Maggiore Policlinico, Medical Oncology Unit, Milan, Italy; ${ }^{9}$ Fondazione IRCCS Ca' Granda Ospedale Maggiore Policlinico, Thoracic Surgery Unit, Milan, Italy

10.1136/oemed-2018-ICOHabstracts.434

Aim of special session To highlight examples and best practice in the area of occupational disease and modelling morbidity.

\section{9a WORK-RELATED DISEASES AMONG FARMERS IN NORWAY: WHAT DO THE DOCTORS REPORT TO THE LABOUR INSPECTORATE REVEAL, AND WHAT THEY MISS?}

${ }^{1} \mathrm{Y}$ Samant, ${ }^{2} \mathrm{HM}$ Gravseth, ${ }^{3} \mathrm{O}$ Aas, ${ }^{1} \mathrm{R}$ Ekle, ${ }^{1} \mathrm{~T}$ Strømholm*.${ }^{1}$ Norwegian Labour Inspection Authority, Norway; ${ }^{2}$ National Institute of Occupational Health, Norway; ${ }^{3}$ St. Olav's Hospital, Division of occupational medicine, Norway

\subsection{6/oemed-2018-ICOHabstracts.435}

Introduction Doctors in Norway report work-related diseases to the Labour Inspection Authority as required by the Working Environment Act. These reports make the basis for the labour inspectorates registry for work-related diseases (RAS). The purpose of this study is to highlight the lack of reliable data with regards to work-related diseases among Norwegian farmers which hinders our preventive efforts.

Methods Data as they concern the occupation 'farmers' were extracted from RAS for the period 2005-2017. The data among others included variables pertaining to demographics, occupational exposures, diagnosis, year of reporting, and the type of doctor who reported the disease. We performed descriptive analysis on the extracted data to obtain frequency, and percentage distribution of the data. We plan to calculate incidence rates; however, it has been difficult to find a reliable denominator for such computations.

Result In the period 2005-2017, 616 cases of work-related diseases among farmers were reported. On average 44 reports of work-related disease among farmers were reported to the Labour Inspectorate annually. $95 \%$ of the reported cases were farmers under the age of 67 years. Hearing loss made up about $60 \%$ $(\mathrm{N}=368)$ of all the cases followed by respiratory diseases that make up $19 \%(\mathrm{~N}=116)$ of all cases. Only a few cases are attributed to other diagnosis groups like skin diseases, musculoskeletal- and psychological disorders.

Discussion The doctors report on work-related diseases among farmer's reveal that hearing loss is still a major challenge. Some of these data are being applied for preventive actions. Having said that, we know from research studies and self-reported data that farmers are exposed to among others dust, gas, pesticides, infectious materials. They work long hours in difficult postures. However, RAS data is missing a large number work-related diseases among the Norwegian farmers which is hindering effective prevention.

\section{9b SOCIO-DEMOGRAPHIC AND OCCUPATIONAL FACTORS ASSOCIATED WITH SUICIDE AMONG FRENCH FARMERS}

V Gigonzac*, I Khireddine-Medouni, E Breuillard, C Bossard, I Guseva Canu, G Santin, L Chérié-Challine. Santé Publique France, French Public Health Agency, Direction of Occupational Health, Saint-Maurice, France

\subsection{6/oemed-2018-ICOHabstracts.436}

Introduction An excessive risk of suicide mortality among farmers has been observed internationally and in France. However, only few studies tried to explore this issue in terms of sociodemographic and occupational determinants and analyse whether they act as risk or as protective factors. The objective of this study was to investigate associations between suicide mortality and socio-demographic and occupational characteristics in the population of French self-employed male farmers between 2007 and 2011.

Methods The study population included all French male selfemployed farmers. Socio-demographic and occupational characteristics were collected from a compulsory social security system for the workers in the agriculture. Causes of death were obtained from the French National Mortality Database. The associations between socio-demographic and occupational characteristics and suicide mortality were examined using a Poisson multivariate regression.

Results Suicide mortality was associated with age between 45 and 54 years (RR 1.60, 95\% CI: 1.24 to 2.06), having an individual farm (RR 1.20, 95\% CI: 1.02 to 1.42 ), a farm area of 20 to 49 hectares (RR 1.47, 95\% CI: 1.03 to 2.10 ) and farming as an exclusive activity (RR 1.66, 95\% CI: 1.29 to 2.14). Farming in several French regions was associated with a higher risk of suicide, whereas type of farming was not.

Discussion The results highlighted differences in suicide mortality among French male farmers according to their socio-demographic and occupational characteristics. This study provides a better understanding of the suicide mortality among farmers and should help to orientate actions prevention. 